\title{
Incidence and risk of venous thromboembolism according to primary treatment type in women with endometrial cancer: a population-based study
}

Jin-Sung Yuk ${ }^{1}$, Banghyun Lee ${ }^{2 *}$, Kidong Kim³ ${ }^{3}$ Myoung Hwan Kim', Yong-Soo Seo ${ }^{1}$, Sung Ook Hwang ${ }^{2}$, Yong Kyoon $\mathrm{Cho}^{1}$ and Yong Beom $\mathrm{Kim}^{3}$

\begin{abstract}
Background: Current prophylaxes and treatments for venous thromboembolism (VTE) in women with gynecologic cancer are mainly guided by studies on solid cancers because studies in gynecologic cancer did not provide sufficient data. Large-scale studies evaluating the incidence and risk of VTE according to therapeutic modality may guide prophylaxis and treatment of VTE in gynecologic cancer. This study was performed to determine the incidence and risk of VTE according to primary treatment type in Korean women with endometrial cancer.

Methods: We selected 26,256 women newly diagnosed with endometrial cancer between 2009 and 2018 from the Korean Health Insurance Review and Assessment Service database. During the total follow-up period and first six months after primary treatments initiation, the incidence and risk of VTE were evaluated according to primary treatment type, that is, no treatment, surgery, radiotherapy, chemotherapy, or hormone therapy.

Results: VTE occurred in 136 per 10,000 women during the total follow-up period and in 54 per 10,000 women during the first six months with the highest frequency in women that underwent chemotherapy. During the first year, the monthly incidence of VTE decreased with time among women that underwent no treatment, surgery, or hormone therapy and remained unchanged in those that received radiotherapy or chemotherapy. Compared with women that received no treatment, VTE risk, especially of PE significantly increased in women that underwent chemotherapy (VTE: hazard ratio (HR), 2.334; 95\% Cl, 1.38-3.949; $P=0.002)(\mathrm{PE}: \mathrm{HR}, 2.742 ; 95 \% \mathrm{Cl}, 1.424-5.278 ; P=$ 0.003) or hormone therapy (VTE: HR, 2.073; 95\% Cl, 1.356-3.17; $P=0.001)(\mathrm{PE}: \mathrm{HR}, 2.086 ; 95 \% \mathrm{Cl}, 1.19-3.657 ; P=0.01)$ during the total follow-up period and women that underwent only chemotherapy during the first six months (VTE: $\mathrm{HR}, 2.532 ; 95 \% \mathrm{Cl}, 1.291-4.966 ; P=0.007)(\mathrm{PE}: \mathrm{HR}, 3.366 ; 95 \% \mathrm{Cl}, 1.496-7.576 ; P=0.003)$.
\end{abstract}

\footnotetext{
* Correspondence: banghyun.lee@gmail.com

${ }^{2}$ Department of Obstetrics and Gynecology, Inha University hospital, Inha University School of Medicine, 27, Inhang-ro, Sinheung-dong, Jung-gu, Incheon, Republic of Korea

Full list of author information is available at the end of the article
}

(C) The Author(s). 2021 Open Access This article is licensed under a Creative Commons Attribution 4.0 International License, which permits use, sharing, adaptation, distribution and reproduction in any medium or format, as long as you give appropriate credit to the original author(s) and the source, provide a link to the Creative Commons licence, and indicate if changes were made. The images or other third party material in this article are included in the article's Creative Commons licence, unless indicated otherwise in a credit line to the material. If material is not included in the article's Creative Commons licence and your intended use is not permitted by statutory regulation or exceeds the permitted use, you will need to obtain permission directly from the copyright holder. To view a copy of this licence, visit http://creativecommons.org/licenses/by/4.0/ The Creative Commons Public Domain Dedication waiver (http://creativecommons.org/publicdomain/zero/1.0/) applies to the data made available in this article, unless otherwise stated in a credit line to the data. 
Conclusions: In this cohort study, the incidence and risk of VTE were highest in women with endometrial cancer that underwent chemotherapy as a primary treatment. Notably, the incidence of VTE decreased over time in women that received no treatment, surgery, or hormone therapy. This study can help guide therapies for prophylaxis and treatment of VTE in women with endometrial cancer.

Keywords: Chemotherapy, Endometrial cancer, Hormone therapy, Surgery, Radiotherapy, Venous thromboembolism

\section{Introduction}

Endometrial cancer is the most common cancer of the female reproductive tract [1], and its incidence has increased due to increases in elderly and obese populations [2]. In addition to hypercoagulability, which is characteristic of cancer, factors such as old age, obesity, surgery, radiotherapy, chemotherapy, and hormone therapy can induce venous thromboembolism (VTE) in women with cancer, including gynecologic cancers $[3$, 4].

VTE, which includes deep vein thrombosis (DVT) and pulmonary embolism (PE), is a common complication of gynecologic cancers [3]. The incidence of VTE in women with gynecologic cancer depends on the type of treatment received (e.g., surgery, radiotherapy, or chemotherapy) [5-19].

When endometrial cancer is suitable for surgery and does not have distant metastasis, the primary treatment comprises total hysterectomy (TH) or radical hysterectomy (RH), bilateral salpingo-oophorectomy (BSO) and lymph node assessment [20]. When endometrial cancer is unsuitable for primary surgery or is accompanied by distant metastasis, primary treatments include external beam radiation therapy (EBRT), brachytherapy, chemotherapy, hormone therapy, or palliative $\mathrm{TH}$ and $\mathrm{BSO}$ [20]. However, although there are various treatments for endometrial cancer, relatively few studies have evaluated the relationship between VTE and therapeutic modality $[6,7,9-13,15,16]$.

Currently, most prophylaxes and treatments for VTE in women with gynecologic cancer are guided by studies on solid cancers, such as lung, stomach, pancreatic, brain, and renal cancer, because studies in gynecologic cancer have not provided sufficient data [3, 4, 21, 22]. We considered that conducting a large-scale study on the incidence and risk of VTE according to therapeutic modality might guide prophylaxis and treatment of VTE in endometrial cancer. Therefore, we evaluated the incidence and risk for VTE according to primary treatment type in women with endometrial cancer using Korean national health insurance data.

\section{Materials and methods}

Approximately $98 \%$ of the Korean population is covered by a universal health coverage system (National Health
Insurance) [23]. The claims data of the Health Insurance Review and Assessment Service (HIRA) include 23 million women per year [23]. In the present study, we used claims data from the HIRA database of women with diagnostic codes for endometrial cancer generated between January 1, 2007, and December 31, 2018. Approval for this study was waived by the Institutional Review Board of Inha University Hospital (No. 2019-11007) on November 25, 2019, because the HIRA dataset uses anonymous identification codes to protect personal information, as is required by the Bioethics and Safety Act in South Korea. Informed consent was not required.

The diagnostic, surgical, and prescription codes used to select eligible women were based on the 10th revision of the International Statistical Classification of Diseases and Related Health Problems (ICD-10), Health Insurance Medical Care Expenses (2017 and 2018 version), and HIRA Drug Ingredients Codes. Using the Korea Central Cancer Registry as a reference, women with endometrial cancer were defined as women with five or more diagnostic codes for endometrial cancer (ICD-10: C54x or C55x) and no diagnostic code for any other cancer between 2007 and 2018. Among women diagnosed with endometrial cancer, women with diagnostic codes for VTE (ICD-10: I80.2, I80.3, I26.0, I26.9) before the first C54x or C55x codes were excluded. Women with C54x or C55x codes between 2007 and 2008 (the wash out period) were also excluded to extract only women with newly diagnosed endometrial cancer. Women with VTE were defined as women that received prescriptions for anticoagulants more than twice simultaneously with diagnostic codes for VTE after the initiation of primary cancer treatment (surgery, radiotherapy, chemotherapy, or hormone therapy). Women who did not receive primary cancer treatment were defined as having VTE if they received prescriptions for anticoagulants more than twice simultaneously with diagnostic codes for VTE from the date of the first diagnostic code for endometrial cancer. DVT and PE cases were defined based on the receipt of more than two prescriptions for anticoagulants under diagnostic codes of I80.2 or I80.3 and I26.0 or I26.9, respectively.

Subject ages were categorized using intervals of 5 years. Low socioeconomic status (SES) was defined as the use of Medicaid as National Health Insurance. 
Charlson Comorbidity Indices (CCIs) were calculated using data obtained between 365 days and 1 day before the first diagnostic date of endometrial cancer, as described by Quan [24]. Primary treatments (no treatment, surgery, radiotherapy, chemotherapy, and hormone therapy) were defined as treatments performed first after diagnosis of endometrial cancer. In the no treatment group, the incidence of VTE after diagnosis of endometrial cancer was evaluated. No treatment was defined as the lack of a prescription code for surgery, radiotherapy, or chemotherapy; women in this category, were diagnosed with endometrial cancer but did not receive surgery, radiotherapy, or chemotherapy.

Surgery was defined using surgery codes for $\mathrm{TH}$ or $\mathrm{RH}$ and the presence of simultaneous diagnostic codes for endometrial cancer. If two or more surgeries were performed, the first surgery was defined as the primary treatment. Radiotherapy was defined as prescription codes for concurrent chemoradiotherapy (CCRT), EBRT (external beam radiation therapy) or brachytherapy with simultaneous diagnostic codes for endometrial cancer. CCRT was defined as codes for EBRT and simultaneous codes for chemotherapy. Chemotherapy was defined as prescription codes for chemotherapy (cisplatin, carboplatin, dacarbazine, docetaxel, doxorubicin, epirubicin, everolimus, gemcitabine, ifosfamide, liposomal doxorubicin, paclitaxel, pazopanib, trabectedin, temozolomide, temsirolimus, topotecan, or bevacizumab) with a simultaneous diagnostic code for endometrial cancer. Hormone therapy was defined as prescription codes for hormone therapy (progestins, tamoxifen, aromatase inhibitors, gonadotropin-releasing hormone agonists, levonorgestrel-releasing intrauterine system) with a simultaneous diagnostic code for endometrial cancer. Use of prophylactic anticoagulants for VTE was defined as the receipt of anticoagulants more than twice without diagnostic codes for VTE after the initiation of primary treatment or from the date of endometrial cancer diagnosis (in the no treatment group). Prescribed anticoagulants included aspirin, direct oral anticoagulants (DOAC), fondaparinux, low molecular weight heparin (LMWH), unfractionated heparin (UFH), and warfarin.

\section{Statistical analyses}

The independent $\mathrm{t}$-test and Mann-Whitney $\mathrm{U}$ test were used for continuous variables, whereas the Chi-square test and Fisher's exact test were used for categorical variables. The Cochran-Armitage trend test was used for trend analysis, and Cox Proportional Hazard Regression analysis with or without adjustment for confounders was used to analyze associations between variables and VTE. Two-tailed tests were used throughout, and $P$ values of $<0.05$ were considered statistically significant. The mean imputation method was used to account for missing values. For analyses, $\mathrm{SAS}^{\triangleright}$ Enterprise Guide ${ }^{\bullet}$ version 6.1 (SAS Institute, Inc., Cary, NC, USA) and R version 3.3.2 ( $\mathrm{R}$ Foundation for Statistical Computing, Vienna, Austria) were used.

\section{Results}

A schematic of the selection process is provided in Fig. 1. Initially, the data of 34,452 women with five or more diagnostic codes for endometrial cancer between 2007 and 2018 were extracted, and 26,256 women with newly diagnosed endometrial cancer from 2009 were finally selected.

\section{Baseline characteristics of women with endometrial cancer}

The 26,256 women with endometrial cancer included were followed up for an average of $1418.9 \pm 6.3$ days. Detailed characteristics of the study subjects are provided in Table 1.

\section{Incidences of VTE according to primary treatment modality types}

During the total follow-up period after primary treatment initiation, VTE occurred in 136 per 10,000 women, with treatment modalities in order of decreasing frequency as chemotherapy, hormone therapy, no treatment and surgery, and radiotherapy. During the first 6 months after primary treatment initiation, VTE occurred in 54 per 10,000 women, with treatments in decreasing order of frequency as chemotherapy, radiotherapy, surgery, and no treatment. VTE was not observed in the hormone therapy group during the first 6 months (Table 2).

During the first year after primary treatment initiation, the monthly incidence of VTE decreased over time in the no treatment, surgery, and hormone therapy groups (Cochran-Armitage trend test: $P<0.001$ ), but did not change with time in the radiotherapy or chemotherapy groups (Fig. 2).

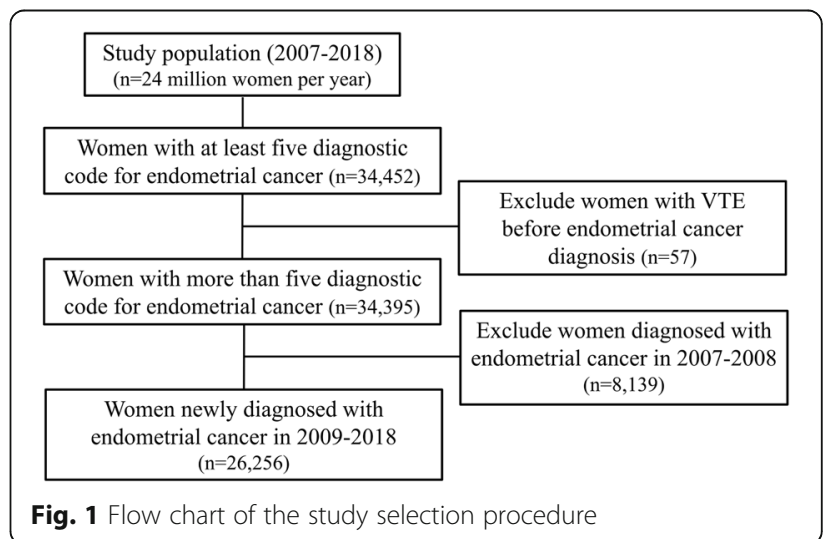


Table 1 Characteristics of women with endometrial cancer

\begin{tabular}{|c|c|c|c|c|c|c|c|c|}
\hline & \multicolumn{4}{|c|}{ The total follow-up period } & \multicolumn{4}{|c|}{ The first six months } \\
\hline & VTE (-) & VTE (+) & Total & & VTE (-) & VTE (+) & Total & \\
\hline & $\begin{array}{l}n=25,899 \\
(98.6 \%)\end{array}$ & $\begin{array}{l}n=357 \\
(1.4 \%)\end{array}$ & $\begin{array}{l}n=26,256 \\
(100 \%)\end{array}$ & $\begin{array}{l}P \\
\text { value }\end{array}$ & $\begin{array}{l}n=26,114 \\
(99.5 \%)\end{array}$ & $\begin{array}{l}n=142 \\
(0.5 \%)\end{array}$ & $\begin{array}{l}n=26,256 \\
(100 \%)\end{array}$ & $\begin{array}{l}P \\
\text { value }\end{array}$ \\
\hline Mean age (years), mean \pm SE & $54.17 \pm 0.1$ & $\begin{array}{l}59.25 \pm \\
0.6\end{array}$ & $54.24 \pm 0.1$ & $<.001^{a}$ & $54.21 \pm 0.1$ & $\begin{array}{l}58.35 \pm \\
0.9\end{array}$ & $54.24 \pm 0.1$ & $<.001^{\mathrm{a}}$ \\
\hline SES, n (\%) & & & & 0.101 & & & & 0.61 \\
\hline Mid- or high- SES & $24,767(95.6)$ & $335(93.8)$ & $25,102(95.6)$ & & $24,965(95.6)$ & $137(96.5)$ & $25,102(95.6)$ & \\
\hline LOW SES & $1132(4.4)$ & $22(6.2)$ & $1154(4.4)$ & & $1149(4.4)$ & $5(3.5)$ & $1154(4.4)$ & \\
\hline $\mathrm{CCl}, \mathrm{n}(\%)$ & & & & $<.001$ & & & & 0.695 \\
\hline 0 & $14,299(55.2)$ & $159(44.5)$ & $14,458(55.1)$ & & $14,387(55.1)$ & $71(50)$ & $14,458(55.1)$ & \\
\hline 1 & $3464(13.4)$ & $48(13.4)$ & $3512(13.4)$ & & $3491(13.4)$ & $21(14.8)$ & $3512(13.4)$ & \\
\hline 2 & $4688(18.1)$ & $76(21.3)$ & $4764(18.1)$ & & $4738(18.1)$ & $26(18.3)$ & $4764(18.1)$ & \\
\hline 3 & $1366(5.3)$ & $24(6.7)$ & $1390(5.3)$ & & $1381(5.3)$ & $9(6.3)$ & $1390(5.3)$ & \\
\hline Over 4 & $2082(8)$ & $50(14)$ & $2132(8.1)$ & & $2117(8.1)$ & 15 (10.6) & $2132(8.1)$ & \\
\hline Year of endometrial cancer diagnosis, n (\%) & & & & 0.101 & & & & 0.016 \\
\hline 2009 & $1991(7.7)$ & $20(5.6)$ & $2011(7.7)$ & & $2007(7.7)$ & $4(2.8)$ & $2011(7.7)$ & \\
\hline 2010 & $2099(8.1)$ & $25(7)$ & $2124(8.1)$ & & $2116(8.1)$ & $8(5.6)$ & $2124(8.1)$ & \\
\hline 2011 & $2238(8.6)$ & $45(12.6)$ & $2283(8.7)$ & & $2268(8.7)$ & $15(10.6)$ & $2283(8.7)$ & \\
\hline 2012 & $2319(9)$ & $32(9)$ & $2351(9)$ & & $2342(9)$ & $9(6.3)$ & $2351(9)$ & \\
\hline 2013 & $2508(9.7)$ & $37(10.4)$ & $2545(9.7)$ & & $2537(9.7)$ & $8(5.6)$ & $2545(9.7)$ & \\
\hline 2014 & $2553(9.9)$ & $38(10.6)$ & $2591(9.9)$ & & $2583(9.9)$ & $8(5.6)$ & $2591(9.9)$ & \\
\hline 2015 & $2686(10.4)$ & $42(11.8)$ & $2728(10.4)$ & & $2707(10.4)$ & $21(14.8)$ & $2728(10.4)$ & \\
\hline 2016 & $3081(11.9)$ & $47(13.2)$ & $3128(11.9)$ & & $3106(11.9)$ & $22(30)$ & $3128(11.9)$ & \\
\hline 2017 & $3326(12.8)$ & $41(11.5)$ & $3367(12.8)$ & & $3342(12.8)$ & $25(17.6)$ & $3367(12.8)$ & \\
\hline 2018 & $3098(12)$ & $30(8.4)$ & $3128(11.9)$ & & $3106(11.9)$ & $22(15.5)$ & $3128(11.9)$ & \\
\hline Primary treatments ${ }^{\mathrm{b}}, \mathrm{n}(\%)$ & & & & 0.1 & & & & $<0.001$ \\
\hline No treatement ${ }^{c}$ & $5268(20.3)$ & 70 (19.6) & $5338(20.3)$ & & $5307(20.3)$ & $31(20)$ & $5338(20.3)$ & \\
\hline Surgery ${ }^{d}$ & $17,386(67.1)$ & $231(64.7)$ & $17,617(67.1)$ & & $17,509(67.1)$ & $108(69.7)$ & $17,617(67.1)$ & \\
\hline Radiotherapy \pm chemotherapy & $544(2.1)$ & $6(1.7)$ & $550(2.1)$ & & $546(2.1)$ & $4(2.6)$ & $550(2.1)$ & \\
\hline Chemotherapy & $723(2.8)$ & $18(5)$ & $741(2.8)$ & & $729(2.8)$ & $12(7.7)$ & $741(2.8)$ & \\
\hline Hormone therapy & $1978(7.6)$ & $32(9)$ & $2010(7.7)$ & & $2010(7.7)$ & $0(0)$ & $2010(7.7)$ & \\
\hline \multicolumn{9}{|l|}{ Surgery, n (\%) } \\
\hline Total hysterectomy & $9874(56.8)$ & $113(48.9)$ & $9987(56.7)$ & 0.016 & $9932(56.7)$ & $55(50.9)$ & $9987(56.7)$ & 0.225 \\
\hline Radical hysterectomy & $7512(43.2)$ & $118(51.1)$ & $7630(43.3)$ & 0.016 & $7577(43.3)$ & $53(49.1)$ & $7630(43.3)$ & 0.225 \\
\hline \multicolumn{9}{|l|}{ Radiotherapy, n (\%) } \\
\hline CCRT & $16(2.9)$ & $1(16.7)$ & $17(0)$ & $0.172^{e}$ & $17(3.1)$ & $0(0)$ & $17(0)$ & $1^{e}$ \\
\hline EBRT & $306(56.3)$ & $5(83.3)$ & $311(86.9)$ & $0.24^{e}$ & $308(56.4)$ & $3(75)$ & $311(86.9)$ & $0.637^{\mathrm{e}}$ \\
\hline Brachytherapy & $313(57.5)$ & $2(33.3)$ & $315(37.4)$ & $0.41^{\mathrm{e}}$ & $314(57.5)$ & $1(25)$ & $315(37.4)$ & $0.318^{e}$ \\
\hline \multicolumn{9}{|l|}{ Chemotherapy, n (\%) } \\
\hline Platinum (cisplatin, carboplatin) & $203(48.2)$ & $11(61.1)$ & $214(48.7)$ & 0.442 & $506(69.6)$ & $8(66.7)$ & $514(69.6)$ & $0.764^{e}$ \\
\hline Other agents & $218(51.8)$ & $7(38.9)$ & $225(51.3)$ & 0.426 & $221(30.4)$ & $4(33.3)$ & $225(30.4)$ & $0.761^{\mathrm{e}}$ \\
\hline Bevacizumab & $16(3.8)$ & $0(0)$ & $16(3.6)$ & $1^{e}$ & $16(2.2)$ & $0(0)$ & $16(2.3)$ & $1^{\mathrm{e}}$ \\
\hline \multicolumn{9}{|l|}{ Hormone therapy } \\
\hline Progestins & $1823(74.6)$ & $29(72.5)$ & $1852(74.5)$ & $0.736^{e}$ & $1852(74.5)$ & $0(0)$ & $1852(74.5)$ & $1^{e}$ \\
\hline Tamoxifen & $49(2)$ & $2(5)$ & $51(2.1)$ & $0.194^{e}$ & $51(2.1)$ & $0(0)$ & $51(2.1)$ & $1^{e}$ \\
\hline
\end{tabular}


Table 1 Characteristics of women with endometrial cancer (Continued)

\begin{tabular}{|c|c|c|c|c|c|c|c|c|}
\hline & \multicolumn{4}{|c|}{ The total follow-up period } & \multicolumn{4}{|c|}{ The first six months } \\
\hline & VTE (-) & VTE (+) & Total & & VTE (-) & VTE (+) & Total & \\
\hline & $\begin{array}{l}n=25,899 \\
(98.6 \%)\end{array}$ & $\begin{array}{l}n=357 \\
(1.4 \%)\end{array}$ & $\begin{array}{l}n=26,256 \\
(100 \%)\end{array}$ & $\begin{array}{l}P \\
\text { value }\end{array}$ & $\begin{array}{l}n=26,114 \\
(99.5 \%)\end{array}$ & $\begin{array}{l}n=142 \\
(0.5 \%)\end{array}$ & $\begin{array}{l}n=26,256 \\
(100 \%)\end{array}$ & $\begin{array}{l}P \\
\text { value }\end{array}$ \\
\hline Progestins and Tamoxifen & $33(1.3)$ & $2(5)$ & $35(1.4)$ & $0.106^{\mathrm{e}}$ & $35(1.4)$ & $0(0)$ & $35(1.4)$ & $1^{e}$ \\
\hline Aromatase inhibitors & $69(2.8)$ & $4(10)$ & $73(2.9)$ & $0.027^{\mathrm{e}}$ & $73(2.9)$ & $0(0)$ & $73(2.9)$ & $1^{\mathrm{e}}$ \\
\hline Gonadotropin-releasing hormone agonists & $21(0.9)$ & $1(2.5)$ & $22(0.9)$ & $0.299^{\mathrm{e}}$ & $22(0.9)$ & $0(0)$ & $22(0.9)$ & $1^{\mathrm{e}}$ \\
\hline Levonorgestrel-releasing intrauterine system & $450(18.4)$ & $2(5)$ & $452(18.2)$ & 0.027 & $452(18.2)$ & $0(0)$ & $452(18.2)$ & $1^{\mathrm{e}}$ \\
\hline $\begin{array}{l}\text { Time between primary treatments and VTE } \\
\text { diagnosis (days), mean } \pm \mathrm{SE}\end{array}$ & & $\begin{array}{l}526.8 \pm \\
46.4\end{array}$ & & & & $79.9 \pm 7.5$ & & \\
\hline
\end{tabular}

$\mathrm{CCl}$ Charlson comorbidity index; CCRT concurrent chemoradiation therapy; EBRT external beam radiation therapy; HIRA health insurance review \& assessment Service; $n$ number; SES socioeconomic status; VTE venous thromboembolism

All values are expressed as mean \pm standard error or number (\%)

${ }^{\text {a }}$ The Mann-Whitney $U$ test was used for this analysis

${ }^{b}$ Primary treatments refers to the first cancer treatments

c Incidence of VTE after diagnosis of endometrial cancer was evaluated

${ }^{d}$ Neoadjuvant chemotherapy followed by laparotomy or laparoscopy was considered as surgery

e The Fisher's exact test was used for this analysis

During the total follow-up period, the incidence of VTE increased according to increase of age in the no treatment, surgery, and hormone therapy groups (Cochran-Armitage trend test: $P<0.001$ ), but no agerelated change was observed in the radiotherapy or chemotherapy group. The incidence of VTE in the surgery group was highest for women aged $20-25$ years and in the chemotherapy group was highest for women aged 30-35 years. Furthermore, the incidences of VTE among women aged 25-30 years that underwent surgery and among those aged 35-40 years that underwent chemotherapy were higher than for women of other ages. These findings may have been due to the relatively small numbers of women with endometrial cancer in these age groups. The incidence of VTE began to decrease at 70 or 75 years of age for all types of primary treatment, except hormone therapy (Additional files 1 and 2).

\section{Relationship between risk factors and VTE occurrence}

During the total follow-up period, the risk of VTE significantly increased according to increased age, CCI, and year of endometrial cancer diagnosis (age: hazard ratio (HR), 1.231; 95\% CI, 1.175-1.29; $P<0.001$ ) (CCI: HR, 1.121; 95\% CI, 1.071-1.173; $P<0.001$ ) (year of endometrial cancer diagnosis: $\mathrm{HR}, 1.112$; $95 \% \mathrm{CI}, 1.064-1.162$; $P<0.001)$. A low SES was not a risk factor of VTE. Receipt of chemotherapy or hormone therapy as primary treatments were associated with significant increases in VTE risk, especially of PE, as compared with no treatment after adjusting for confounders (chemotherapy: VTE: HR, 2.334; 95\% CI, 1.38-3.949; $P=0.002$ ) (chemotherapy: PE: HR, 2.742; 95\% CI, 1.424-5.278; $P=0.003)$ (hormone therapy: VTE: HR, 2.073; 95\% CI, 1.356-3.17; $P=.001$ ) (hormone therapy: PE: HR, 2.086; 95\% CI, $1.19-3.657 ; P=0.01$ ), but surgery and radiotherapy were

Table 2 Incidences (per 10,000 women) of VTE according to primary treatments

\begin{tabular}{|c|c|c|c|c|c|c|c|c|c|c|c|c|c|}
\hline & \multicolumn{6}{|c|}{ The total follow-up period } & \multicolumn{6}{|c|}{ The first six months } & \multirow{3}{*}{$\begin{array}{l}\text { Total } \\
\text { cases }\end{array}$} \\
\hline & \multicolumn{2}{|l|}{ VTE } & \multicolumn{2}{|l|}{ DVT } & \multicolumn{2}{|l|}{$\underline{\mathrm{PE}}$} & \multicolumn{2}{|l|}{ VTE } & \multicolumn{2}{|l|}{ DVT } & \multicolumn{2}{|l|}{$\mathrm{PE}$} & \\
\hline & Count & Incidence & Count & Incidence & Count & Incidence & Count & Incidence & Count & Incidence & Count & Incidence & \\
\hline \multicolumn{14}{|l|}{ Primary treatments ${ }^{a}$} \\
\hline No treatment ${ }^{b}$ & 70 & 131 & 33 & 62 & 41 & 77 & 31 & 58 & 13 & 24 & 18 & 34 & 5338 \\
\hline Surgery ${ }^{c}$ & 231 & 131 & 120 & 68 & 127 & 72 & 108 & 61 & 50 & 28 & 63 & 36 & 17,617 \\
\hline Radiotherapy & 6 & 109 & 4 & 73 & 3 & 55 & 4 & 73 & 3 & 55 & 2 & 36 & 550 \\
\hline Chemotherapy & 18 & 243 & 7 & 94 & 12 & 162 & 12 & 162 & 3 & 40 & 9 & 121 & 741 \\
\hline $\begin{array}{l}\text { Hormone } \\
\text { therapy }\end{array}$ & 32 & 159 & 14 & 70 & 18 & 90 & 0 & 0 & 0 & 0 & 0 & 0 & 2010 \\
\hline Total cases & 357 & 136 & 178 & 68 & 201 & 77 & 142 & 54 & 64 & 24 & 84 & 32 & 26,256 \\
\hline
\end{tabular}

DVT deep vein thrombosis; HIRA Health Insurance Review \& Assessment Service; PE pulmonary embolism; VTE venous thromboembolism

a Primary treatments refers to the first cancer treatments

${ }^{b}$ Incidence of VTE after diagnosis of endometrial cancer was evaluated

c Neoadjuvant chemotherapy followed by laparotomy or laparoscopy was considered as surgery 


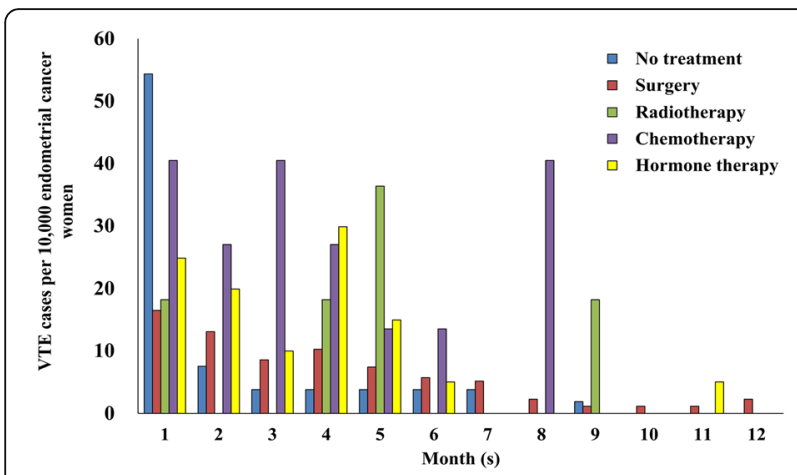

Fig. 2 Monthly incidences of VTE during the first year after primary treatment initiation. In women that received no treatment, the incidence of VTE after diagnosis of endometrial cancer was evaluated

not found to influence VTE risk as compared with no treatment (Table 3).

During the first 6 months, the risk of VTE significantly increased according to increased age and year of endometrial cancer diagnosis (age: HR, 1.147; 95\% CI, 1.066$1.235 ; P<0.001$ ) (year of endometrial cancer diagnosis: HR, 1.124; 95\% CI, 1.057-1.194; $P<0.001)$. Low SES, and CCI were not risk factors of VTE. Chemotherapy (as the only treatment) was associated with a significant increase in VTE risk, especially for PE, as compared with no treatment after adjustment for confounders (VTE: HR, 2.532; 95\% CI, 1.291-4.966; $P=0.007$ ) (PE: HR, 3.366; 95\% CI, 1.496-7.576; $P=0.003$ ) (Table 3).

\section{Incidence of VTE according to use of the prophylactic anticoagulants after primary treatments}

During the total follow-up period, $14.5 \%$ of women with endometrial cancer received prophylactic anticoagulants. Moreover, $6.2 \%$ of women with VTE did not undergo prophylactic anticoagulant therapy $(4.5 \%$ of DVT and $7 \%$ of PE cases) and 93.8\% underwent prophylactic anticoagulant therapy (95.5\% of DVT and $93 \%$ of PE cases). VTE occurred in $0.1 \%$ ( $0 \%$ of DVT and $0.1 \%$ of PE cases) of women that did not receive prophylactic anticoagulant therapy and in $8.8 \%$ (4.5\% of DVT and $4.9 \%$ of PE cases) of women that underwent prophylactic anticoagulant therapy (Additional file 3).

Prescribed prophylactic anticoagulants, in decreasing order of frequency, were UFH (78.0\%), DOAC (16.5\%), warfarin (15.7\%), LMWH (11.9\%), and fondaparinux (0.1\%). The most frequently used therapeutic anticoagulant was DOAC (59.1\%), and an inferior vena cava filter was used in $5.9 \%$ of women with VTE (Additional file 4).

\section{Discussion}

Our study demonstrated the highest incidence of VTE during the total follow-up period and during the first 6 months occurred in women with endometrial cancer administered chemotherapy as a primary cancer treatment. The monthly incidence of VTE decreased with time during the first year in the no treatment, surgery, and hormone therapy groups but did not change in the radiotherapy or chemotherapy groups. Furthermore, the risk of VTE was greater for women that underwent chemotherapy or hormone therapy than for those that received no treatment.

Reported incidences of VTE in women with endometrial cancer range between 0.35 and $8 \%[6,7,9-13,15$, $16,25]$. In the present study, VTE incidences agreed with those previously reported $(1.4 \%$ during the total follow-up period and $0.5 \%$ during the first 6 months). In one cohort study, the absolute rate of VTE in women with endometrial cancer $(n=1958)$ decreased over time after cancer diagnosis [26]. In another two cohort studies, the incidence of VTE decreased over time for 30 $(n=175)$ and 90 days $(n=4158)$ following gynecologic cancer surgery $[27,28]$, and in a fourth cancer cohort study conducted on a claims database $(n=17,284)$, the incidence of VTE decreased over time during the 12 months following the initiation of chemotherapy [18]. Similarly, we found that in the no treatment, surgery, and hormone therapy groups, the incidence of VTE decreased with time during the first year after primary cancer treatment initiation. However, in our radiotherapy and chemotherapy groups, no longitudinal change in the incidence of VTE was observed. Further studies are needed to clarify VTE occurrence trends with respect to time for different primary cancer treatment types.

Previous studies have reported incidences of $0.35-8 \%$ for VTE in women with endometrial cancer that have undergone surgery (open or minimally invasive surgery including staging surgery) $[6,7,9-13,15,16]$, and incidences of $0-13.8 \%$ in women with ovarian, cervical, or endometrial cancer that have undergone surgery [5-16]. In one cohort study, VTE occurred in $1.2 \%$ of women that had undergone gynecologic brachytherapy for cervical, endometrial, or vaginal cancer $(n=329)$ [17], and in a claims database analysis of women with ovarian cancer $(n=1880)$, the incidence of VTE was reported to be $11 \%$ during the first year after the initiation of chemotherapy [18]. In a cohort study performed on women with cervical cancer $(n=798)$, the incidence of VTE was $33.8 \%$ among women that received chemotherapy, and chemotherapy was found to be a risk factor of VTE [19]. In another cohort study performed on women with ovarian cancer $(n=328)$, non-receipt of treatment for cancer was a risk factor of VTE [29]. In our study, the incidence of VTE was highest for chemotherapy (2.4\%) followed in decreasing order of frequency by hormone therapy $(1.6 \%)$, no treatment $(1.3 \%)$, surgery $(1.3 \%)$, and radiotherapy (1.1\%) during the total follow-up period, 


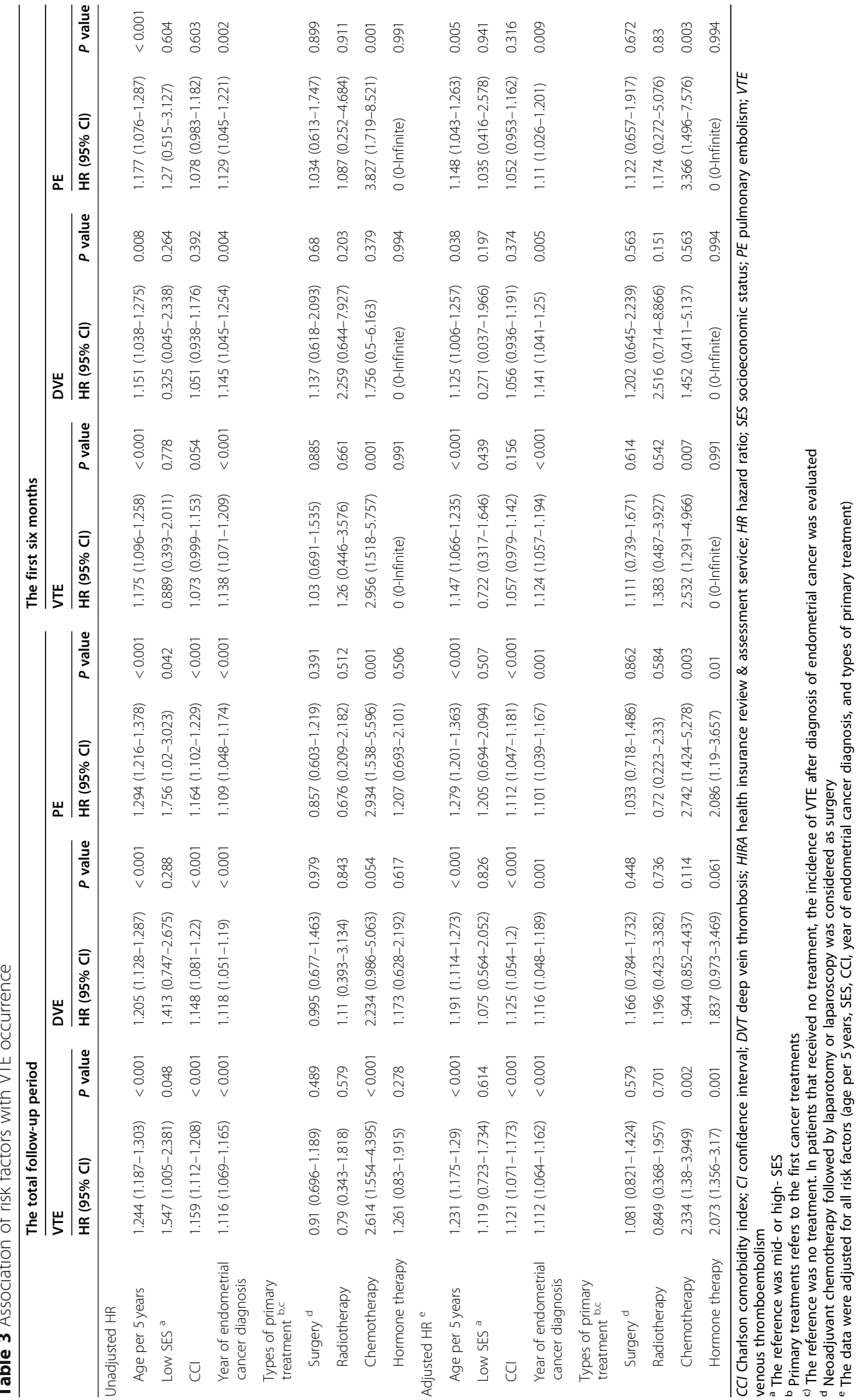


and chemotherapy (1.6\%), radiotherapy $(0.7 \%)$, surgery $(0.6 \%)$, no treatment $(0.6 \%)$, and hormone therapy $(0 \%)$ during the first 6 months of follow-up. Furthermore, compared with women that received no treatment, VTE risk, especially for $\mathrm{PE}$, was significantly higher in women that received chemotherapy or hormone therapy during the total follow-up period and was significantly higher for women that underwent chemotherapy at six-month follow-up visits. It has been reported that sudden fatal PE event is a leading cause of VTE-related deaths in medical and surgical patients [30]. Current guidelines recommend that anticoagulant treatment for VTE prophylaxis during systemic chemotherapy may be considered for ambulatory cancer patients at intermediate or high risk of VTE (Khorana score $\geq 2$ ) [4, 31, 32]. Furthermore, gynecologic cancers are considered high risk by the Khorana predictive model for chemotherapyassociated VTE [32], and women with endometrial cancer that receive chemotherapy as a primary treatment usually have advanced disease and are at high risk for VTE $[4,20]$. Therefore, our findings that chemotherapy as a primary therapeutic modality is a risk factor of VTE and associated with the highest incidence of VTE support the use of anticoagulants to prevent chemotherapyassociated VTE in women with endometrial cancer that receive chemotherapy as a primary treatment.

In a study of women with endometrial cancer treated by surgical staging $(n=714)$, the incidence of VTE was greater in women older than 60 years than in women younger than 60 years $(10.7 \%$ vs $7.1 \%)$ [11]. Similarly, in another endometrial cancer cohort $(n=1958)$, the absolute rate of VTE was higher in women over 60 years than in women under 60 years (13 per 1000 person years vs 7 per 1000 person years) [26]. In our study, regardless of follow-up duration after primary treatments initiations, women with VTE were older than women without, and the risk of VTE increased with age. In addition, we observed changes in VTE occurrence according to primary treatment type and age. Interestingly, for all types of primary treatment, except hormone therapy, we found the incidence of VTE decreased from 70 or 75 years of age. We suggest this finding be confirmed by further study.

In our study, $14.5 \%$ of women with endometrial cancer underwent prophylactic anticoagulant treatment during the total follow-up period, and the incidence of VTE were higher in those that received prophylactic treatment. We believe that women exposed to VTE risk factors such as old age, high CCI, radical hysterectomy, chemotherapy, or hormone therapy are likely to receive prophylactic anticoagulant treatments more frequently.

This nationwide, population-based cohort study provides more data than multicenter studies. Furthermore, it is the first to evaluate the incidence and risk of VTE in a large cohort according to primary treatment in women with a diagnosis of endometrial cancer and to examine relationships between chemotherapy or hormone therapy and VTE. Limitations of this study are associated with analysis using claims data. First, diseases were defined using diagnostic and prescription codes, and medical records were not reviewed, and thus, a few women coded incorrectly may have been misdiagnosed. Second, women that received prescriptions for anticoagulants less than twice were not considered to have VTE. Based on the coverage provided by the Korean national health insurance system, women with VTE are usually treated regardless of symptoms, and thus, we believe only a small proportion of those affected were not treated for VTE. Third, women with VTE before endometrial cancer diagnosis or initiation of primary cancer treatments were not included. If diagnosis of VTE or endometrial cancer and initiation of primary cancer treatment occurred within a short time frame, it is possible that the order of diagnosis was inaccurate. Finally, we did not evaluate relationships between VTE and BMI or stage or histologic type of endometrial cancer because the HIRA dataset did not provide this information. Nonetheless, our study indicates primary treatment presents a greater risk of VTE than no treatment, which might be because of the dependence of treatment modality on stage.

This retrospective analysis of claims data presents the incidence and risk of VTE and time to VTE occurrence according to primary treatment type in women with endometrial cancer. We hope that the results of this study help guide the prophylaxis and treatment of VTE, which is a serious complication in women with endometrial cancer.

\section{Abbreviations}

VTE: Venous thromboembolism; DVT: Deep vein thrombosis; PE: Pulmonary embolism; TH: Total hysterectomy; RH: Radical hysterectomy; BSO: Bilateral salpingo-oophorectomy; EBRT: External beam radiation therapy; HIRA: Health insurance review and assessment service; ICD-10: The 10th revision of the international statistical classification of diseases and related health problems; SES: Socioeconomic status; CCIs: Charlson comorbidity indices; CCRT: Concurrent chemoradiotherapy; DOAC: Direct oral anticoagulants; LMWH: Low molecular weight heparin; UFH: Unfractionated heparin

\section{Supplementary Information}

The online version contains supplementary material available at https://doi. org/10.1186/s12885-021-08853-x

\footnotetext{
Additional file 1: Supplemental Figure 1. Incidences of VTE according to age in women with endometrial cancer (based on HIRA claims data for 2009-2018). In women that received no treatment, the incidence of VTE after diagnosis of endometrial cancer was evaluated.

Additional file 2: Supplemental Table 1. Incidences of VTE according to age in women with endometrial cancer (based on HIRA claims data for 2009-2018). In women that received no treatment, the incidence of VTE after the diagnosis of endometrial cancer was evaluated.
} 
Additional file 3: Supplemental Table 2. Incidences of VTE according to prophylactic anticoagulant use in women with endometrial cancer (based on HIRA claims data for 2009-2018).

Additional file 4: Supplemental Table 3. Methods of VTE prophylaxis and treatment in women with endometrial cancer (based on HIRA claims data for 2009-2018).

\section{Acknowledgements}

We thank the Health Insurance Review and Assessment Service for providing data (HIRA- M20191230191) for this study.

\section{Authors' contributions}

JSY, BL, KK and MHK conceptualized the study, and designed the methodology. JSY and BL analyzed the study, interpreted the results, and wrote the manuscript (original draft preparation). BL acquired funding and performed supervision. BL, YSS, SOH, YKC and YBK participated in the review \& editing of the manuscript. All authors read and approved the final manuscript.

\section{Funding}

This work was supported by an INHA UNIVERSITY HOSPITAL Research Grant. However, it had no involvement in study design, the collection, analysis and interpretation of data, the writing of the report, and the decision to submit the paper for publication.

\section{Availability of data and materials}

The data that support the findings of this study are available from the Health Insurance Review and Assessment Service (HIRA) but restrictions apply to the availability of these data, which were used under license for the current study, and so are not publicly available. Data are however available from the authors upon reasonable request and with permission of the HIRA.

\section{Declarations}

\section{Ethics approval and consent to participate}

Approval for this study was waived by the Institutional Review Board of Inha University Hospital (No. 2019-11-007). Informed consent had not been applied due to the retrospective nature of the study.

\section{Consent for publication}

Not applicable.

\section{Competing interests}

The authors have no conflict of interest or financial ties to disclose.

\section{Author details}

'Department of Obstetrics and Gynecology, Sanggye Paik Hospital, School of Medicine, Inje University, Seoul, Republic of Korea. ${ }^{2}$ Department of Obstetrics and Gynecology, Inha University hospital, Inha University School of Medicine, 27, Inhang-ro, Sinheung-dong, Jung-gu, Incheon, Republic of Korea. ${ }^{3}$ Department of Obstetrics and Gynecology, Seoul National University Bundang Hospital, Seongnam-Si, Gyeonggi-Do, Republic of Korea.

Received: 22 April 2021 Accepted: 7 October 2021

Published online: 30 October 2021

\section{References}

1. Van Nyen T, Moiola CP, Colas E, Annibali D, Amant F. Modeling endometrial Cancer: past, present, and future. Int J Mol Sci. 2018;19(8):2348. https://doi. org/10.3390/ijms19082348.

2. Cancer E. In: Hoffman BL, Schorge JO, Schaffer JI, Halvorson LM, Bradshaw KD, Cunningham F, editors. Williams Gynecology. 2nd ed. New York, NY: McGraw-Hill; 2012. p. 817.

3. Cohen A, Lim CS, Davies AH. Venous thromboembolism in gynecological malignancy. Int J Gynecol Cancer. 2017;27(9):1970-8. https://doi.org/10.1 097/IGC.0000000000001111.

4. National Comprehensive Cancer Network. Cancer-Associated Venous Thromboembolic Disease (Version 1.2020) [cited 2020 Dec 20] Available from: https://www.nccn.org/professionals/physician_gls/pdf/vte.pdf
5. Panici PB, Plotti F, Zullo MA, Muzii L, Manci N, Palaia I, et al. Pelvic lymphadenectomy for cervical carcinoma: laparotomy extraperitoneal, transperitoneal or laparoscopic approach? A randomized study. Gynecol Oncol. 2006;103(3):859-64. https://doi.org/10.1016/j. ygyno.2006.05.025.

6. Backes FJ, Brudie LA, Farrell MR, Ahmad S, Finkler NJ, Bigsby GE, et al. Shortand long-term morbidity and outcomes after robotic surgery for comprehensive endometrial cancer staging. Gynecol Oncol. 2012;125(3): 546-51. https://doi.org/10.1016/j.ygyno.2012.02.023.

7. Kodama J, Seki N, Fukushima C, Kusumoto T, Nakamura K, Hongo A, et al. Elevated preoperative plasma D-dimer levels and the incidence of venous thromboembolism in Japanese females with gynecological cancer. Oncol Lett. 2013;5(1):299-304. https://doi.org/10.3892/ol.2012.970.

8. Yhim HY, Jang MJ, Bang SM, Kim KH, Kim YK, Nam SH, et al. Incidence of venous thromboembolism following major surgery in Korea: from the Health Insurance Review and Assessment Service database. J Thromb Haemost. 2014;12(7):1035-43. https://doi.org/10.1111/jth.12611.

9. Freeman $\mathrm{AH}$, Barrie A, Lyon L, Littell RD, Garcia C, Conell C, et al. Venous thromboembolism following minimally invasive surgery among women with endometrial cancer. Gynecol Oncol. 2016;142(2):267-72. https://doi. org/10.1016/j.ygyno.2016.06.002.

10. Kim JS, Mills KA, Fehniger J, Liao C, Hurteau JA, Kirschner CV, et al. Venous thromboembolism in patients receiving extended pharmacologic prophylaxis after robotic surgery for endometrial Cancer. Int J Gynecol Cancer. 2017;27(8):1774-82. https://doi.org/10.1097/IGC.0000000000001084.

11. Moeini A, Machida H, Takiuchi T, Blake EA, Hom MS, Miki T, et al. Association of Nonalcoholic Fatty Liver Disease and Venous Thromboembolism in women with endometrial Cancer. Clin Appl Thromb Hemost. 2017;23(8): 1018-27. https://doi.org/10.1177/1076029616665925.

12. Laskov I, Kessous R, Abitbol J, Kogan L, Badeghiesh A, Tagalakis V, et al. SOGC communities of practice risk of thromboembolic disease with cost estimates in patients undergoing robotic assisted surgery for endometrial cancer and review of the literature. J Obstet Gynaecol Can. 2018;40(12): 1571-9. https://doi.org/10.1016/j.jogc.2018.04.003.

13. Kahr HS, Christiansen OB, Høgdall C, Grove A, Mortensen RN, Torp-Pedersen $C$, et al. Endometrial cancer does not increase the 30-day risk of venous thromboembolism following hysterectomy compared to benign disease. A Danish National Cohort Study. Gynecol Oncol. 2019;155(1):112-8. https://doi. org/10.1016/j.ygyno.2019.07.022.

14. Wagner BE, Langstraat $C L$, McGree ME, Weaver AL, Sarangi S, Mokri B, et al. Beyond prophylaxis: extended risk of venous thromboembolism following primary debulking surgery for ovarian cancer. Gynecol Oncol. 2019;152(2): 286-92. https://doi.org/10.1016/j.ygyno.2018.11.021.

15. Carbajal-Mamani SL, Dideban B, Schweer D, Balavage KT, Chuang L, Wang Y, et al. Incidence of venous thromboembolism after robotic-assisted hysterectomy in obese patients with endometrial cancer: do we need extended prophylaxis? J Robot Surg. 2020;2021. https://doi.org/10.1007/s11 701-020-01110-6. Online ahead of print.

16. Pin S, Mateshaytis J, Ghosh S, Batuyong E, Easaw JC. Risk factors for venous thromboembolism in endometrial cancer. Curr Oncol. 2020;27(4):198-203. https://doi.org/10.3747/co.27.5981.

17. Dusenbery KE, Carson LF, Potish RA. Perioperative morbidity and mortality of gynecologic brachytherapy. Cancer. 1991;67(11):2786-90. https://doi. org/10.1002/1097-0142(19910601)67:11<2786::AID-CNCR2820671112>3.0. $\mathrm{CO} ; 2-\mathrm{H}$.

18. Khorana AA, Dalal M, Lin J, Connolly GC. Incidence and predictors of venous thromboembolism (VTE) among ambulatory high-risk cancer patients undergoing chemotherapy in the United States. Cancer. 2013;119(3):648-55. https://doi.org/10.1002/cncr.27772.

19. Matsuo K, Moeini A, Machida H, Fullerton ME, Shabalova A, Brunette LL, et al. Significance of venous thromboembolism in women with cervical cancer. Gynecol Oncol. 2016;142(3):405-12. https://doi.org/10.1016/j.ygyno.2 016.06.012.

20. National Comprehensive Cancer Network. Uterine neoplasms (Version 1. 2021) https://www.nccn.org/professionals/physician_gls/pdf/uterine.pdf (accessed 2020 Dec 20).

21. Lyman GH, Khorana AA, Falanga A, Clarke-Pearson D, Flowers C, Jahanzeb $M$, et al. American Society of Clinical Oncology guideline: recommendations for venous thromboembolism prophylaxis and treatment in patients with cancer. J Clin Oncol. 2007;25(34):5490-505. https://doi.org/10.1200/JCO.2 007.14.1283. 
22. Geerts WH, Bergqvist D, Pineo GF, Heit JA, Samama CM, Lassen MR, et al. Prevention of venous thromboembolism: American College of Chest Physicians Evidence-Based Clinical Practice Guidelines (8th Edition). Chest. 2008;133(6 Suppl):381s-453s.

23. Kim L, Kim JA, Kim S. A guide for the utilization of Health Insurance Review and Assessment Service national patient samples. Epidemiol Health. 2004; 36:e2014008. https://doi.org/10.4178/epih/e2014008.

24. Quan H, Li B, Couris CM, Fushimi K, Graham P, Hider P, et al. Updating and validating the Charlson comorbidity index and score for risk adjustment in hospital discharge abstracts using data from 6 countries. Am J Epidemiol. 2011;173(6):676-82. https://doi.org/10.1093/aje/kwq433.

25. Austin K, George J, Robinson EJ, Scully M, Thomas MR. Retrospective cohort study of venous thromboembolism rates in ambulatory Cancer patients: association with Khorana score and other risk factors. Hematol. 2019;8(1):1725. https://doi.org/10.14740/jh471.

26. Walker AJ, Card TR, West J, Crooks C, Grainge MJ. Incidence of venous thromboembolism in patients with cancer - a cohort study using linked United Kingdom databases. Eur J Cancer. 2013;49(6):1404-13. https://doi. org/10.1016/j.ejca.2012.10.021.

27. Ruff SM, Weber KT, Khader A, Conte C, Kadison A, Sullivan J, et al. Venous thromboembolism in patients with cancer undergoing surgical exploration. J Thromb Thrombolysis. 2019;47(2):316-23. https://doi.org/10.1007/s11239018-1774-3.

28. Peedicayil A, Weaver A, Li X, Carey E, Cliby W, Mariani A. Incidence and timing of venous thromboembolism after surgery for gynecological cancer. Gynecol Oncol. 2011;121(1):64-9. https://doi.org/10.1016/j.ygyno.2010.11.03 8.

29. Trugilho IA, Renni MJP, Medeiros GC, Thuler LCS, Bergmann A. Incidence and factors associated with venous thromboembolism in women with gynecologic cancer. Thromb Res. 2020;185:49-54. https://doi.org/10.1016/j. thromres.2019.11.009.

30. Gerotziafas GT, Samama MM. Prophylaxis of venous thromboembolism in medical patients. Curr Opin Pulm Med. 2004;10(5):356-65. https://doi.org/1 0.1097/01.mcp.0000136947.31517.c4.

31. Key NS, Khorana AA, Kuderer NM, Bohlke K, Lee AYY, Arcelus Jl, et al. Venous thromboembolism prophylaxis and treatment in patients with Cancer: ASCO clinical practice guideline update. J Clin Oncol. 2020;38(5): 496-520. https://doi.org/10.1200/JCO.19.01461.

32. Khorana AA, Kuderer NM, Culakova E, Lyman GH, Francis CW. Development and validation of a predictive model for chemotherapy-associated thrombosis. Blood. 2008;111(10):4902-7. https://doi.org/10.1182/blood-2 007-10-116327.

\section{Publisher's Note}

Springer Nature remains neutral with regard to jurisdictional claims in published maps and institutional affiliations.

Ready to submit your research? Choose BMC and benefit from:

- fast, convenient online submission

- thorough peer review by experienced researchers in your field

- rapid publication on acceptance

- support for research data, including large and complex data types

- gold Open Access which fosters wider collaboration and increased citations

- maximum visibility for your research: over $100 \mathrm{M}$ website views per year

At BMC, research is always in progress.

Learn more biomedcentral.com/submissions 